ON

\section{THE SUBCUTANEOUS SECTION OF BOILS AND CARBUNCLES.}

BY JOHN GEORGE FRENCH, F.R.C.S., SURGEON TO THE INFIRMIIRT OF ST. JAMES, WESTMINSTER.

I Have been much interested in the perusal of the clinical lecture of Mr. Paget on the Natural History of Carbuncle, published in The Lancer of the 16th instant; and, having been a severe student of this subject, $I$ am able to recognise the truthfulness of the description given of it.

But in the objections raised to the active surgical interference in the treatment-for which, as far as the subcutaneous section is concerned, I deem myself responsible,Mr. Paget uses the following argument: "Nay, in some cases, carbuncles completely abort."

The whole philosophy of the subcutaneous section is involved in this suggestion; and is contained in the following aphorism:-The complete division of the indurated tissue always causes the abortion of carbuncle. This, of course, implies early interference; for the term "abortion" can hardly apply to an advanced development.

Those who wish to compare the relative value of the natural course of the disease with that of subcutaneous section, may select for the former observation patients whose time is unimportant; and for the latter, those having important business or social engagements to fulfil, in which time is an essential element.

In studying the course of the disease, I have been in the habit of dotting the boundary line of redness with ink or colour, to show me the exact extent and direction of any spreading of the inflammation. By this means I am convinced, after numerous trials, that, where the subcutaneous section has been made, inflammation does not extend in the direction of the knife.

Mr. Paget speaks of the mortality of the disease as probably representing two per cent., although regarded by the profession generally as far more dangerous. I am quite sure that the cases in St. James's Infirmary have far exceeded 200 during the last thirty-eight years, and the mortality has been only two; but there was this peculiarity in both eases, which involves a point of great interest and importance-namely, that the disease occurred on the anterior surface of the body. In one, a male, the carbuncle was in front of the neck, extending on either side beyond the ear; and, when the slough separated, the bloodvessels were revealed to sight as well as the denuded muscles. In the other, a female, the carbuncle was on the abdomen, with extensive diffuse erysipelas. This case was not brought to notice until shortly before death, the patient concealing her malady, and unwillingly complaining. It would be interesting to know if any of the four fatal cases recorded by Mr. Paget were on the anterior surface of the body.

I have certainly regarded carbuncles on the anterior aspect as being attended with more danger than those on the posterior surface, and have had in my infirmary during the last year two cases in the front of the thigh, both in males, entailing danger by their proximity to the large bloodvessels. They both recovered.

In speaking of treatment Mr. Paget attaches due importance to cleanliness and "keeping the surface of the skin adjacent to the carbuncle perfectly dry and free from any contact with the discharge, which seems really to have the power of infecting the neighbouring skin, and so producing the boils which are apt to arise sometimes in clusters around the carbuncle." To avert this evil, I have, most successfully, used cotton wool instead of poultice.

I am also quite sure Mr. Paget is right in reference to the diet which he recommends, of which the following may serve as an example:-

T. O-, aged eighty, an inmate of St. James's Workhouse, twelve years ago had a carbuncle, for which he was attended by Mr. Bowman, of Dalston; and, being then in easy circumstances, he was recommended to take a bottle of port wine daily: this he did for six weeks, the time which it took to heal. Last year he was admitted into the infirmary with a carbuncle, the induration being about the size of an egg; this was divided subcutaneously, and upon the ordinary infirmary diet he was quite well in a little more than a week.

Great Marlborough-street, Jan. 1869.

\section{ON THE FLUID OF HYDROCEPHALUS}

BY CHAS. MEYMOTT TIDY, M.B., C.M.,

JOINT LECTCRER OY CHIAISTRT AT THE LONDOY HOSPITAL.

I HAve to acknowledge the kindness of Dr. Woodman and Mr. Heckford in preserving the fluid in a case of hydrocephalus, and forwarding it to me for analysis.

The following is au abstract of the notes of the case as sent me by Mr. Hechford:-

The child came under his care when it was four months old. It was born hydrocephalic. The head steadily increased in size, and when he first saw it it measured twentysix inches in circumference. Mr. Heckford tapped the head with a No. 1 trocar on the right side, an inch and a half from the middle line, in the space between the frontal and parietal bones. Two days after the operation it had an attack of convulsions. A month after this Mr. Heckford tapped it again, and it was this fluid I examined. The child had taken two grains of iodide of potassinm from his first seeing it. Previous to the last operation both eyes were rotated downwards, but the pressure being now removed from the orbital plates, the position of the eyes has become almost natural.

The liquid was turbid; numerous floceuli were seen floating in it. It had a specific gravity of $1007^{\circ} 6$.

1000 grains of the fluid yielded $5 \cdot 18$ grains of solid matter. This consisted of-

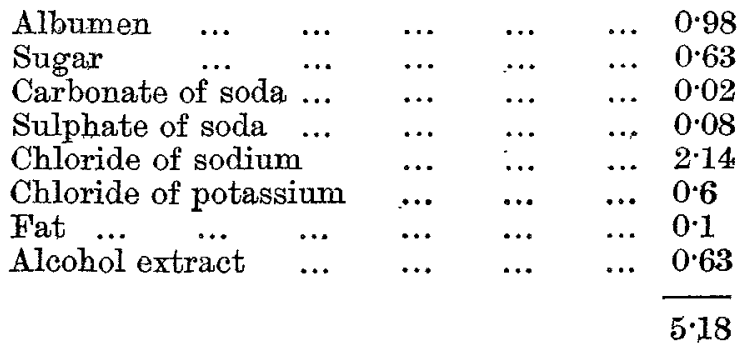

Cambridge-heath, Hackney, Dec. 1868.

ON A CASE OF

\section{ISCHURIA RENALIS, ICTERUS, AND LOW PNEUMONIA COMBINED.}

BY JOHN M. BRYAN, I.R.C.P.I., Moreton-in-Marsh.

MRs. $\mathrm{R}$ present time an active old lady, of dark, rather sallow complexion, above the average height, and slightly made, was placed under my care on Sunday, Sept.13th, 1868. During the previous week she had been complaining of a bilious feeling, stars floating in front of her eyes, \&c. On the morning of the 11th her friends noticed how ill she looked, and made the expressive remark that if ten years had passed over her head, since the day before, she could not have appeared older than she then looked. On the 12th she appeared very ill, and was scarcely able to get out of her chair, but never complained of pain; and her indisposition was attributed by her friends to over-exertion and exposure to cold. She had never suffered from gout, nor could I make out any previous history of kidney disease ; indeed, she had scarcely ever been laid up with any illness except bilious attacks.

On the 13th Mrs. R- seemed very ill, and scarcely able to support herself in her chair, She was downstairs. Her pulse was 90 , small and weak; tongue moist and covered with a whitish fur, browner at the sides ; no pain or tenderness in abdomen; the bowels had been opened the night before; loss of appetite; said she thought she had a bilious attack, and complained of giddiness, \&c. I recommended 